\title{
SITING ENCOUNTERS AND ENCOUNTERING SITES: CONTEMPORARY NARRATIVE GEOGRAPHIES
}

\author{
Kari Meyers Skredsvig
}

\begin{abstract}
RESUMEN
Este artículo, el tercero de una serie que analiza las relaciones entre mujer y espacio, examina las relaciones significativas entre la geografía (espacio/lugar) y la literatura, en términos de su desarrollo cronológico, sus funciones y sus repercusiones. Dentro de las contemplaciones literarias del espacio, el concepto de "geografía" ha evolucionado de lugar físico a sitio imaginario de la construcción del ser y de la inserción socio-ideológica. Las teorías literarias contemporáneas se han apropiado de construcciones geográficas para examinar textos de manera innovadora, de la misma forma en que los autores de esos textos se han apropiado de la literatura para forjar posiciones propias.
\end{abstract}

\begin{abstract}
The following article, the third of a series which examines connections between women and space, examines significant relationships between geography (space/place) and literature, in terms of their chronological development, their functions, and their repercussions. In literary considerations of space, the concept of geography has evolved from indicating physical place to imaginary sites of selfconstruction and socio-ideological insertion. Contemporary literary theories have appropriated geographical constructs to examine texts in innovative ways, just as the authors of those texts have appropriated literature to forge positions of their own.
\end{abstract}

Literature has a longstanding relationship with time and space which runs the gamut from reaffirming to challenging to transforming their significance. And while the merging of time and space is so traditional that it is frequently assumed as a given, poststructuralist theories continuously remind us that we can no longer take the directions or shape of either time or space for granted. Like a subtly shifting kaleidoscope, the passage of time concomitantly alters its spatial counterpart(s); just as time has lost its linearity, so space has become increasingly amorphous. As the new millenium begins to take shape -both literally in sociopolitical and economic terms, and metaphorically in psychological and philosophical terms- humans are simultaneously reconfiguring an entire network of spaces. Initiation of the new millenium does more, however, than merely induce us to change: it demands it. In contemporary academia, one of the most intriguing and significant changes has been the increasingly interdisciplinary nature of fields of inquiry, from transgression of strictly observed borders of differentiation to opacity and even transmutation of their assigned areas. For space is not just inhabited: it is also appropriated, appraised, exploited, denied, imagined, inscribed, and negotiated, among a myriad 
of other space-related activities. Contrary to common misconceptions, space is neither passive nor impartial, but rather a dynamic site of cultural encounter.

Recent changes in literary studies bear testimony to the above. Contemporary critical trends all but require that the modern literary critic be not only familiar with but knowledgable about psychology, history, linguistics, sociology, mythology, politics, economics and philosophy, to identify major areas, all of which can be (and are) complicated by a seemingly infinite number of subdivisions. For traditionalists, these modern alignments of literature with areas which were previously clearly differentiated is disconcerting at best, sacrilegious at worst. Many of these critics, trained in essentially intrinsic approaches to literature such as The New Criticism or even more traditional moral-philosophical perspectives, perceive contemporary tendencies toward interdisciplinary approaches as somehow contaminating the science and/or denigrating the art of literary criticism. Others welcome the innovations but seem rather overwhelmed by the challenge of reconciling "literary" concerns with "nonliterary" ramifications. It is an intrepid critic, indeed, who is willing to go out on a literary limb, so to speak, by venturing into the uncharted spaces encompassed within contemporary literary studies. That said, the unparalleled opportunities which these new perspectives open up must also be acknowledged; traditional critical formulas have given way to a new kind of critical inquiry which prides itself more on the quality of its questions than the quantity of its answers. And although it could justifiably be argued that each new alliance invariably (inevitably?) claims its own modicum of authenticity and truth (usually presented in terms of ascribed validity rather than prescribed veracity), the very diversity of these approaches and the very nature of their challenges to traditional criticism undermine, if not impede, any attempted claims of ultimate truth or authority.

Within these spaces of critical encounters, the unexpected coalition of literary and geographical studies constitutes one of the most recent and most promising. Traditionally, any pairing of the two has been in a quite literal sense. For example, literary historians have examined connections between literature and space through regionalist and nationalist movements manifested in literature. In the literary history of the U.S., as I have examined in previous articles, this has translated into the ipso facto appropriation of literature for the purposes of establishing and reinforcing a national identity through claimed uniqueness. For example, the early eighteenth-century frontier novels of James Fenimore Cooper not only explored the novelty of New World settings, but also propagated a New World hero, the "rugged individualist" so treasured in U.S. social mythology. Cooper's penchant for historical fiction and social commentary has lead to his being considered a (and sometimes "the") foundational figure for the U.S. novel tradition, as well as largely responsible for nineteenth-century European perceptions of the people and places of the U.S. Likewise, the New England sketches and stories of Washington Irving, Cooper's contemporary, exploited local settings, characters, and events both to literally disassociate their New World from the Old and also to forge a distinct literary identity by diverging from dominant European literary standards of the time, especially as a precursor of the short story genre. Evidence of Irving's success is clear in the fact that he is lauded as the first U.S. author to make a living from his writing, and indeed, has even been heralded as the "father of U.S. literature". The thrust of these early alliances of place and literature was arguably as political as it was literary, although not necessarily intentionally so.

In the subsequent development of U.S. literature, the most obvious juncture of literature and space was the Regionalist Movement of the latter half of the nineteenth century, 
which actually incorporated, although it is sometimes seen as synonymous with, the local color fiction of the time. Once again, the literary tendency is closely aligned with the socio-political context. Regionalism as a movement evolved in the post-Civil War (1861-1865) period of the U.S. and is generally perceived as having culminated in the late 1880 s or early 1890 s. There tend to be two juxtaposed readings of why it developed at that time. The first sees it as an attempt to reconcile the different areas of the U.S., in the wake of the rents caused by the Civil War, through an appeal to shared patriotism couched in a rather passive acknowledgement of diversity. The second attributes its rise to regional insistence on uniqueness which resists any attempts to homogenize diversity. In either case, the tenacity with which place is employed as symbolic representation of identity, whether national or regional, is clear evidence of its privileged place in the literature of the time. It is worth mentioning, also, that regionalism as a type of literature -rather than a movement-continues to be a common means of identifying and differentiating both authors and content in U.S. literature, for example, in Willa Cather's "prairie novels" and William Faulkner's literary rendition of the South.

Another significant manner in which place and literature have traditionally been combined is in formalists' emphasis on the importance of setting in literary texts, especially fiction. At the very least, setting is perceived as the necessary locus of action, thus one of the basic components of every prose narrative. In this sense, setting encompasses not only physical location and physical features, but also the historical time and particular social milieu (value systems, predominant attitudes, customs, concerns, norms, living style, and so forth). It can be as limited as the time of day and the physical arrangement of a single room, or as expansive as the era and area of the world in question. A story's setting can also be "psychological" in the sense that it may "take place" in the mind of the narrator, such as in Katherine Porter's "The Jilting of Granny Weatherall." Formalists examine both the functions of each basic element of fiction and their interaction in constructing a whole; setting is thus analyzed in terms of its possible constitution of or contribution to establishing character, atmosphere, and/or theme, among others. For example, the lugubrious detailed description of the House of Usher, in Poe's story by the same name, establishes an atmosphere of foreboding, parallels the deterioration of the protagonist, and foreshadows the plot development. Setting can even function as a character itself, as in Joseph Conrad's “The Tale." While formalist analyses of setting are a rich source of textual interpretation, they are insistently intrinsic, concerned solely with the internal setting(s) of the literary text and excluding any context outside of the text itself.

Traditional historical approaches to fiction expand the object of study beyond textual boundaries, but tend to operate on the premise that literature is merely a reflection of the sociohistorical context which has produced it. While this would seem to be ascribing greater significance to setting -since it takes into consideration not only textual but also materialist contexts- in reality, it continues to relegate setting to a relatively passive role. To a large extent, this happens because traditional historical approaches tend to conceptualize history as linear and objective, as "the" account of chronological events rather than as "an" account of a complex web of conditions and situations configuring a much more amorphous whole. The key difference is that the former unquestioningly accepts the "official" version of history, an acceptance reinforced by its perception of language as transparent and meanings as fixed, which contrasts with the "new" historical approaches to literature which acknowledge the ideological multiplicity in every society by perceiving all history as narration and language as 
polysemic. For example, a traditional historical analysis of Washington Irving's "Rip Van Winkle" would highlight the local historical details, such as the founding of New York by the "Knickerbockers" and the birth of the new nation while Van Winkle slept, as background to the life-story of the protagonist, while a "new historicist" analysis would consider the opposition of gender roles and how they are paralleled in the mountain men versus the townspeople, in terms of their ideological import and contribution to the hegemonic (patriarchal, democratic) position Irving foments. In both cases, space and place are given importance; significantly, however, in traditional historical approaches setting is essentially passive (static) background, while in contemporary historicist approaches it is perceived as dynamic and variable.

In literary theory, New Historicism, which developed in the 1980s, and cultural studies, which began to take shape (and happily refuses to keep that shape) in the 1950s and 1960s but has become considerably more institutionalized in the last two decades, have been major contributors to the deconstruction and reconstruction of traditional concepts and uses of space. Paul Hamilton defines historicism as the name given to the "relativizing of the past by getting to know the different interpretations to which it is open and deciding between them on grounds expressing our own contemporary preoccupations" (19). In "Professing the Renaissance: The Poetics and Politics of Culture," Louis Montrose reminds us that "[r]epresentations of the world in written discourse are engaged in constructing the world, in shaping the modalities of social reality, and in accommodating their writers, performers, readers, and audiences to multiple and shifting subject positions with the world they both constitute and inhabit" (16). Montrose also suggests an explanation for the resistance often found in traditional literary criticism to the "thick" contextualizing of literary texts:

\footnotetext{
Inhabiting the discursive spaces traversed by the term "New Historicism" are some of the most complex, persistent, and unsettling of the problems that professors of literature attempt variously to confront or to evade: Among them, the essential or historical bases upon which "literature" is to be distinguished from other discourses; the possible configurations of relationship between cultural practices and social, political and economic processes; the consequences of post-structuralist theories of textuality for the practice of an historical or materialist criticism; the means by which subjectivity is socially constituted and constrained; the processes by which ideologies are produced and sustained, and by which they may be contested; the patterns of consonance and contradiction among the values and interests of a given individual, as these are actualized in the shifting conjunctures of various subject positions [...] (19).
}

As Montrose makes clear, the manner and degree to which critics contextualize texts is one of the most fundamental aspects of the relationship(s) between space and literature in literary studies today. The premises and concepts of new historicist and cultural studies approaches have concomitantly developed from and contributed to contemporary critical trends such as post-colonial studies, gender studies, gay and lesbian studies, queer theory, and border studies, all of which challenge hegemonic appropriations of social space and canonical appropriations of literary space.

Perhaps the most crucial word linking contemporary literary studies and space/geography is "position," especially in its gerund form, "positioning," which emphasizes the premise that every position is active and variable. Contemporary theories privilege the issue of position -always understood as a specific point within a gamut of position possibilities- in examining the role(s) and response(s) of the author, the critic, and reader, and even the text itself. In refering to any of the aforementioned participants, post-structuralist 
analysis is likely to focus on the "subject" rather than the "individual". As Montrose explains, "“[s]ubject', a simultaneously grammatical and political term, has come into widespread use not merely as a fashionable synonym for 'The Individual' but precisely in order to emphasize that individuals and the very concept of 'The Individual' are historically constituted in language and society" (21). He posits the following usage of "subject":

\footnotetext{
...my invocation of the term "Subject" is meant to suggest an equivocal process of subjectification: on the one hand, shaping individuals as loci of consciousness and initiators of action-endowing them with subjectivity and with the capactiy for agency; and, on the other hand, positioning, motivating, and constraining them within-subjecting them to- social networks and cultural codes that ultimately exceed their comprehension or control (21).
}

Montrose's understanding of the concept of "subject" is representative -a word I use with some trepidation in the present context- of post-structuralist stances both in its insistence on the contextualization of the reader/author/critic and in its acknowledgement that each of them is simultaneously individually and collectively constituted.

Another key contemporary concept relating spatialization and literature is the issue of "the gaze," a term borrowed from film studies where it refers to the way filmmakers construct the vision of the spectator. Originally employed by feminist film critics to identify the hegemonic, patriarchal preemption of agency and its resultant objectification of women and their diminishment to passive roles, its usage has now expanded. For example, post-colonial critics and theorists have appropriated it to highlight the ways in which colonial powers have marginalized the colonized by viewing them and representing them as "other." Cultural theorists such as Trinh T. Minh-ha, Edward Said, Gloria Anzaldúa, and Gayatri Spivak have pointedly and poignantly demonstrated to the world that terms such as "Third World," "nonwhite," "women writers," "Western," "non-aligned," and so forth, no matter how "politically correct" in their intent, inevitably take the (Western, white, male) dominant group as their point of reference, thus claiming the central position and simultaneously relegating all other positions to the margins. This unavoidable positioning of the subject-geographically, metaphorically, and ideologically- permeates every text, literary or otherwise, and tends to heighten difference through an opposition of subject (the one viewing) and object (the one viewed), which are themselves closely related to issues of agency and voice. The power is always in the gaze of the spectator whose perceptions are being transmitted, rather than in those being represented.

In narratology, this concept has frequently been denominated "focalization," which theorist Mieke Bal defines as "[t]he relation between the vision and that which is 'seen,' perceived" (100), following Gérard Genette's distinction in Narrative Discourse. Bal objects to the use of "point of view" or "narrative perspective" because they traditionally refer to both the narrator and the vision and also have the disadvantage of having no derivative verb form to emphasize the agent performing the act of narration, which Bal emphasizes is different from the agent that sees. Bal also differentiates between external and internal focalization, as well as levels of focalization. Steven Cohan and Linda Shires clarify in the following manner: "The narrating agent of a text and its 'point of view' are not the same. Agency raises the question of who supplies the narration, while point of view raises the question of whose vision determines what is being narrated" (94). Linguists and semioticians, such as Emile Benveniste, have further distinguished between the "subject of the enunciation" (the agent producing an utterance) and 
the "subject of the utterance" (the linguistic object). Without going into further detail, what interests me about these distinctions for present purposes is their subtle influences upon the positioning of both the teller and the told in narrative. They are strategies for situating the narrator and the narrated which, ideally, also enhance the reader's awareness of his own subject position as a receiver/consumer/co-author/rewriter/interpreter of the literary text.

The crucial importance of both literal and metaphorical positioning in contemporary literary studies is manifested in its appropriation of terminology traditionally associated with geography. Reader-response critics and semioticians speak of "maps of reading and writing," by which they mean the culturally constructions which guide -or, according to some, even determine- our perceptions and articulation of the same. Robert Scholes asserts, in classic Derridean fashion, that "we are never outside the whole web of textuality in which we hold our cultural being and in which every text awakens echoes and harmonies" (6). He further connects this to subject formation by affirming that "[1] earning to read books -or pictures, or films- is not just a matter of acquiring information from texts, it is a matter of learning to read and write the texts of our lives" (19), even though by the time "we become aware of ourselves, we are already thoroughly developed as textual creatures [...] already shaped by powerful cultural texts" (27). Scholes suggests that different approaches to literature are essentially different ways of making sense of the world (91), and that "we need protocols of reading for the same reason that we need other codes and customs - because we desire a framework in which to negotiate our differences" (31). According to Scholes, reading is always a "rewriting of the text of the work within the text of our lives" (10): "In processing a narrative text we actually construct the story, bringing a vast repertory of cultural knowledge to bear upon the text that we are contemplating. Our pleasure in the narrative is to some extent a constructive pleasure, based upon the sense of accomplishment we achieve by successfully completing this task" (122). In other words, as readers we both situate the text within ourselves and position ourselves in relation to the text, thus making not only every reading a rewriting, but also every writing a reading of the larger text outside us.

Perhaps this siting of encounters and encountering of sites is what has prompted Michel de Certeau to affirm that "[e]very story is a travel story-a spatial practice" (qtd. in Friedman 132). Far beyond traditional definitions of the kinesics of narrative as merely involving a movement "from here to there," whether of plot or of character, contemporary narrative motion "signifies" at intangible levels rather than at physical levels. It is precisely in the establishment of positions by reader, writer, and text alike, and their subsequent shifts and transformations. In contemporary theory, this is sometimes refered to as "geographic ideology," which is defined by Indira Karamcheti in "The Geographics of Marginality" as "a kind of epistemological cartography" (126); she follows Said's employment of "imaginative geography" as the discourse which "enables readers and writers alike, whether in the dominant First or the marginalized Third Worlds, to generate textual meaning" by "draw[ing] upon codes of reading common to interpretive communities [...]" (127). Because all textuality implies spacial insertion, textual practices themselves may then be analyzed in terms of centers and margins, borders, intersections, locations and dislocations, boundaries and frontiers, to name a few. Narratology intersects with cultural studies in examining such issues as "gender mapping," "social terrains," "territorial imperatives," "the politics of trespass," and so forth. Because fictional (and other) texts are ineluctably positioned by the very fact of their 
narration, they become "sites of struggle" among genders, classes, ethnicities, cultures, etc., which both writers and readers "chart".

This appropriation of geographical terms is intimately connected with renewed interest in, and newly perceived possibilities of, space as symbolic representation. Gaston Bachelard was among the first to explicitly (re)address perceptions and conceptions of space in literary texts, in The Poetics of Space, originally published in 1958. Although primarily concerned with domestic spaces and how they function metaphorically, especially in poetry, Bachelard drew attention to what had previously been considered a relatively insignificant aspect of literature in general and pioneered what has become a near revolution in our theoretical considerations of literary space. Bachelard's stated intent is to delve into the "ontology" of the poetic image, which he perceives as a direct "reverberation" of being in the imagination, "apprehended in [...] actuality" (xviii). He examines such elements as shells, corners, nests, and drawers, but gives greatest importance to different parts of our homes, which he calls "our first universe." Bachelard also asserts that "all really inhabited space bears the essence of the notion of home" (5), which provides a significant clue as to why space has been so crucial in the literary imagination. In today's rapidly changing world, however, even "home" itself has tended to become symbolic, as theorist bell hooks asserts:

\footnotetext{
home is no longer just one place. It is locations. Home is that place which enables and promotes varied and everchanging perspectives, a place where one discovers new ways of seeing reality, frontiers of difference. One confronts and accepts dispersal and fragmentation as part of the constructions of a new world order that reveals more fully where we are, who we can become $[\ldots]$ (148).
}

Examination of symbolic spaces seems to require their "grounding" in tangible places. J. Hillis Miller's study of space as place, Topographies, not only acknowledges that fact but takes it one step further in his affirmation that toponymy, the naming of places, is the crucial transition from the abstract to the "real": "Place names make a site already the product of a virtual writing, a topography, or, since the names are often figures, a 'topotropography.' With topotropography, the act of mapping, goes topology, the knowledge of places [...]" (4). According to Miller, topography combines the Greek words topos - place- and graphein - to write, a combination which also creates an etymological precursor of the symbolic significance of space in literary texts. The potential for representational import is reinforced by Miller's assertion that every topography hides "a place that is everywhere and nowhere $[. .$.$] an unplaceable place [. . .$.$] which$ inhabits the individual psyche" (7). In other words, the tangible, physical features not only constitute the landscapes of our lives but provide sites for inscribing our lives. Miller, like others we have seen, sees narrative space and places as means for self-realization: "The encrypted place generates stories that play themselves out within a topography. Narration is a way to talk about it, which means personifying it. Such personifications, like prosopopoeias in general, seem a form of knowledge but are in fact potent speech acts. They have to do with doing rather than knowing" (8). In such discussions of topographies, the symbolic importance of place is made clear in the recognition that all physical mappings are accompanied by psychological and mental mappings and that naming is a fundamental performative act.

Another type of "grounding" appears in psychological and sociological theories of subject formation, which highlight the multiple ways in which the construction of identities is related to space and place through identification and differentiation, transforming private versus 
public, individual versus collective, and external versus internal into crucial sites. Poststructuralist theories of identity tend to see subject formation as a complex, dynamic, web of connections and disassociations, alliances and oppositions, dominations and subordinations. Susan Friedman employs the term "geographical rhetoric of identity" to indicate "the locational and spatial configurations of identity understood as forms of multiple, relational, and situational positionalities," which she asserts "arise out of a dialectical or dialogic oscillation between [....] alterity and mimesis, between the sameness and difference that is embedded in the double meaning of the term identity (meaning the the same as, but also relationally different from)" (143). Individuals and cultures alike attain degrees of self-definition-both construct themselves and are constructed--through their interactions and intersections with others. Friedman affirms that identity is "unthinkable" without some kind of imagined or literal boundary; however, she also perceives borders as proclaiming not only separation but also connection. Further complicating this, as Doreen Massey has pointed out, is the fact that "social relations of space are experienced differently, and variously interpreted, by those holding different positions as part of it" (3). Both reject essentialist notions of identity, seeing identity instead as a continuous process: "identities are themselves narratives of formation, sequences moving through space and time as they undergo development, evolution, and revolution" (Friedman 8).

The parallelism between fluctuating identities and shifting spaces corresponds to innovative concepts of place and space. According to social geographer Linda McDowell, places are "constituted by sets of relations which cut across spatial scales," but "touch the ground as spatially located patterns and behaviors" (30); in other words, "places as territorially bounded spaces at different spatial scales are social constructions too" (31). Along similar lines, Massey has articulated four basic premises underlying what she calls a "progressive concept of place": 1) it is emphatically not static; 2) boundaries (in the sense of divisions which enclose) are not necessary; 3) places are full of internal conflicts and do not have "single, unique "identities""; and 4) the specificity (uniqueness) of place and its importance are continually reproduced (but not fixed)" (155). Just as our concept of self is grounded in place, our concept of place is grounded in identity. This makes space contested territory in multiple ways: social, personal, ideological, psychological. It also makes fiction an inhabited site of identity narrative. Friedman suggests that the momentum for narrative comes not so much from desire, as much recent narrative theory has posited, but from the confrontation of self and other: "it is the story of self-other confrontation, spatially located and articulated, that provides the narrative with its donée [.... The story resides in its spaces, its symbolic geographies and the movement among them" (138). She sees space as historically produced and constructed, which to her makes narrative movement more locational than developmental.

When space and place are perceived as social constructions rather than fixed, neutral entities or givens, they are imbued with a significance far beyond the traditional in our lives and in our literature. Poststructuralist theories have prompted productive questioning of the functions and the importance of place which have made the literary text itself a site of struggle. Marginalized groups of all kinds -feminist, gay and lesbian, post-colonialist, and other socalled "minority" groups- have not only raised awareness of how their social, literary, and personal spaces have been appropriated, exploited, and mispresented by hegemonic groups; they have also used literature to (re)claim their voice, (re)occupy their own spaces, (re)define themselves, and (re)create their own places, both literally and metaphorically. For literature 
also occupies space-spaces which are cultural, psychological, political, and aesthetic, and all of which are negotiable. In a narrow sense, all narrative depends on geography for a home, a place to exist; in a much larger sense, narrative itself constitutes the story of who we are, when we are, and where we are, consciously or otherwise. The contemporary alliance of literary studies and geography is much more than a simple novelty or trend: it is a long overdue acknowledgment of the epistemological significance of place in the ways in which we "inhabit" ourselves -our perceptions, the ways we make sense out of our world and position ourselves within it, and our constructions of self. Geographic perspectives expand our literary horizons exponentially, not only by transgressing traditional borders of academic disciplines, but also by opening new theoretical, creative, and living spaces.

\section{Bibliography}

Bachelard, Gaston. 1994. The Poetics of Space. 1958. Trans. Maria Jolas. Boston: Beacon Press.

Bal, Mieke. 1985. Narratology: Introduction to the Theory of Narrative. Trans. Christine van Boheemen. Toronto: U Toronto P.

Cohan, Steven and Linda M. Shires. 1988. Telling Stories: A Theoretical Analysis of Narrative Fiction. New York: Routledge.

Currie, Mark. 1998. Postmodern Narrative Theory. New York: St. Martin's Press.

Friedman, Susan Stanford. 1998. Mappings: Feminism and the Cultural Geographies of Encounter. Princeton, NJ: Princeton UP.

Grossberg, Lawrence et al. (Eds.) 1992. Cultural Studies. New York: Routledge.

Hamilton, Paul. 1996. Historicism. New York: Routledge.

Higonnet, Margaret R. and Joan Templeton (Eds.). 1994. Reconfigured Spheres: Feminist Explorations of Literary Space. Amherst: U Massachussetts P.

Hooks, Bell. 1990. Yearning: Race, Gender, and Cultural Politics. Boston: South End Press.

Karamcheti, Indira. 1994. "The Geographics of Marginality: Place and Textuality in Simone Schwarz-Bart and Anita Desai." Reconfigured Spheres. Margaret R. Higonnet and Joan Templeton (Ed.): 125-46.

Massey, Doreen. 1994. Space, Place, and Gender. Minneapolis: U. Minnesota P. 
McDowell, Linda. 1999. Gender, Identity, \& Place: Understanding Feminist Geographies. Minneapolis: U Minnesota P.

Miller, J. Hillis. 1995. Topographies. Stanford, CA: Stanford UP.

Montrose, Louis. 1989. "Professing the Renaissance: The Poetics and Politics of Culture." The New Historicism. H. Aram Veeser (Ed.).

Onega, Susana and José Angel García Landa (Eds.). 1996. Narratology. New York: Longman.

Scholes, Robert. 1989. Protocols of Reading. New Haven: Yale UP.

Veeser, H. Aram (Ed.). 1989. The New Historicism. New York: Routledge. 